\title{
A Tortura em Foco A Contribuição do Caso Grego para o Direito Internacional
}

\author{
Carmem Letícia da Maia Pereira \\ Mestranda em Direito pela Pontifícia Universidade \\ Católica do Paraná. Bolsista Capes. Membro do núcleo \\ Constitucionalismo e Democracia e do Núcleo de Estu- \\ dos sobre o Sistema Interamericano de Direitos Humanos \\ - Nesidh - ambos do Programa de Pós-Graduação da \\ UFPR. carmem07leticia@gmail.com
}

\section{Flávia Cristina Piovesan}

Professora doutora em Direito Constitucional e Direitos Humanos da Pontifícia Universidade Católica de São Paulo. Professora de Direitos Humanos dos Programas de Pós-Graduação da Pontifícia Universidade Católica de São Paulo, da Pontifícia Universidade Católica do Paraná e da Universidade de Pablo de Olavide (Sevilha, Espanha). Pesquisadora visitante do Programa de Direitos Humanos da Harvard Law School (1995 e 2000), pesquisadora visitante do Centro de Estudos sobre o Brasil da Universidade de Oxford (2005), pesquisadora visitante do Instituto Max Planck (Heidelberg -2007 e 2008); secretária dos Direitos Humanos. flaviapiovesan@terra.com.br

\section{Resumo:}

0 presente artigo pretende analisar a relevância do Caso Grego para a elaboração do atual conceito internacional do crime de tortura. Tendo em vista que foi por meio do Tribunal Penal de Nuremberg, criado para julgar as atrocidades cometidas durante o nazismo, que violações aos direitos humanos 
foram tratadas de forma internacional, o que existia era apenas um conceito geral de crime lesa-humanidade. Com o advento da ditadura grega, contudo, a Comissão Europeia de Diretos Humanos não pôde se eximir de tratar de violações de direitos humanos positivados em sua Convenção. Assim, pela primeira vez no Direito Internacional, o crime de tortura seria analisado, e se iniciaria a construção do conceito internacional atual do crime de tortura. Desta forma, é por meio da análise do caso em questão que é possível demonstrar como o conceito de lesa-humanidade pode ser delimitado, principalmente no que diz respeito à tortura, e por consequência, melhor aplicado.

Palavras-chave: Tortura. Direitos humanos. Caso Grego. Sistema europeu de proteção dos direitos humanos. Crime lesa-humanidade.

\title{
The focus on torture: the contribution of the Greek case to international law
}

\begin{abstract}
This article intent to analyze the relevance of the Greek case to the development of the current international concept of the crime of torture. Given that it was through the Criminal Court of Nuremberg, set up to try the atrocities of Nazism, that human rights violations were dealt with international way, that there was only a general concept of crime against humanity. However, with the advent of the Greek dictatorship, the European Commission of Human Rights could not refrain from addressing human direct violations positivized in its Convention. Thus, for the first time in international law, the crime of torture would be analyzed and would begin the construction of the current international concept of the crime of torture. Thus, it is through case analysis it is possible to demonstrate how the concept of crimes against humanity can be defined, particularly with regard to torture, and therefore better applied.
\end{abstract}

Keywords: Torture. Human rights. Greek Case. European system of human rights protection. Crime against humanity.

\section{Sumário}

1 Introdução. 2 Para além do próprio quintal: A tortura como um crime de lesa-humanidade. 3 Panorama geral da Comissão Europeia de Direitos Humanos - CEDH. 4 A ditadura grega e a atuação da Comissão Europeia de Direitos Humanos - CEDH. 5 Conclusões sobre as consequências para crime de tortura. 6 Referências 


\section{INTRODUÇÃO}

O presente texto tem por objetivo, ao fazer um estudo de caso, expor a relevância do Caso Grego para o conceito de tortura como crime lesa-humanidade e o impacto disso para a análise, o tratamento e julgamento deste. Isso se justifica por que foi apenas com tal Caso que o crime de tortura foi examinado de forma minuciosa, estabelecendo novas formas (como a necessidade de ser cometido por agentes públicos), e novos manejos (devido à dificuldade de fazer prova em tais casos).

Para um pleno entendimento destes objetivos é necessário primeiramente compreender o tamanho e o impacto de tal crime, que normalmente é subestimado. Por isso, na primeira parte é demonstrado como o crime de tortura é algo comum não só na realidade brasileira, ainda que aqui apresente-se em números alarmantes, mas também no mundo todo. Tendo seu ápice em âmbito global com a Segunda Guerra Mundial e o nazismo, o tema da tortura como crime lesa-humanidade foi abordado pelo Tribunal Penal de Nuremberg, no entanto apenas de forma superficial, o que torna a análise feita pela Comissão Europeia de Direitos Humanos no Caso Grego a precursora do conceito do crime como temos hoje.

Após expor a vagueza normativa anterior ao caso aqui analisado e a sua devida relevância nacional e internacional, a segunda parte abordará a formação da Comissão Europeia de Direitos Humanos e o seu funcionamento. É de imprescindível relevância a análise do funcionamento dos processos e procedimentos envolvendo o Caso, além da situação do momento histórico de tal instituição, para que o mérito e as críticas devidas possam ser feitas às mudanças inferidas ao crime de tortura trazido pela decisão do Caso Grego.

Numa terceira parte será finalmente abordado o Caso Grego em questão, revelando inicialmente o seu contexto histórico, ou seja, como o golpe militar se deu na Grécia e os impactos disso para a sociedade grega 
e para o mundo da época. Além disso, será nessa parte que o desenvolvimento do Caso perante a jurisdição da Comissão Europeia de Direitos Humanos será abordado, mostrando o concomitante aparecimento e o destaque das instituições internacionais de direitos humanos. Também é aqui que serão feitos os devidos apontamentos sobre o crime de tortura como modalidade do lesa-humanidade, e a relevância e impacto desse tratamento dado pela Comissão para a aplicação no Direito Internacional.

Em suma, trilhando esse caminho pretende-se mostrar que foi somente com o Caso Grego que o tratamento e as garantias relacionados ao crime de tortura que temos no Direito Internacional atualmente foi possível. E isto é feito por que é comum discutir sobre o crime de tortura como lesa-humanidade, mas é pouco discutido como ele tomou a forma que tem hoje, ainda que seu impacto na jurisprudência internacional de direitos humanos seja constante. Sabe-se muito sobre outros casos que se apoiam na decisão do Caso Grego, mas este é pouco ou nada analisado, o que, se alterado, pode trazer ainda mais benefícios para os casos que envolvem crimes de lesa-humanidade com tortura.

\section{PARA ALÉM DO PRÓPRIO QUINTAL: A Tortura Como Um Crime De Lesa-Humanidade}

Recentemente foi divulgado o relatório "Julgando a tortura: análise de jurisprudência nos tribunais de justiça do Brasil (2005-2010)” (ORGANIZAÇÃO..., 2010) que mostra como esse crime se apresenta: quais suas vítimas, quais os principais acusados, qual o seu propósito, e por fim, como os tribunais nacionais têm decidido.

Os dados apresentados evidenciaram a diferença do tratamento entre os casos de agentes públicos e privados no país. Constatou-se que a tortura é praticada em espaços de custódia, por agentes públicos com fortes vínculos de grupo, contra sujeitos indefesos. A consequência disso 
é a posterior limitação dessas vítimas, posto que há dificuldade de acesso aos recursos e informações, bem como a criação de estigmas referentes às próprias vítimas, o que acaba por prejudicar a comprovação dos fatos, resultando muitas vezes em impunidade.

Os problemas relacionados à tortura são uma realidade comum não apenas no Brasil, mas também e principalmente nos países que vivenciaram um período ditatorial. Como um problema de âmbito global e histórico, a Comissão Europeia de Direitos Humanos (CEDH) foi o primeiro órgão internacional a definir o crime de tortura, diferenciando-o dos demais tratamentos cruéis, degradantes e desumanos, ao se deparar com o Caso Grego (ANDREAS PAPANDREOU FOUNDATION, 1998).

Anteriormente à análise do Caso Grego pela $\mathrm{CEDH}$, havia apenas a noção geral de crime lesa-humanidade, que é gênero do qual o crime de tortura é espécie. Tal gênero de crime é assim definido pela Organização das Nações Unidas:

\begin{abstract}
Assassinato, extermínio, a escravidão, a deportação e qualquer outro ato inumano contra a população civil, ou a perseguição por motivos religiosos, raciais ou políticos, quando esses atos ou perseguições ocorram em conexão com qualquer crime contra a paz ou em qualquer crime de guerra (ORGANIZAÇÃO..., 2009, p. 372).
\end{abstract}

Esses crimes foram tipificados no Estatuto do Tribunal de Nüremberg, o qual foi responsável por julgar os crimes cometidos pelo Estado alemão durante o nazismo. O Estatuto elenca quatro elementos centrais para a caracterização de um crime lesa-humanidade demonstrando suas características gerais:

Incluem o cometimento de atos inumanos, como o assassinato, perpetrados em um contexto de ataque generalizado ou sistemático contra uma população civil. Basta que dentro do contexto descrito só um ato ilícito como os mencionados seja cometido, para que se produza um crime lesa-humanidade. 


\section{(...)}

está diante de um crime contra a humanidade quando: (i) comete-se um ato inumano em sua natureza e caráter; (ii) quando esse ato é cometido como parte de um ataque sistemático ou generalizado; (iii) quando esse ataque responde a uma política que não necessariamente deve haver sido adotada de maneira formal; e (iv) quando o ataque é dirigido contra população civil.

(...)

Crimes contra a humanidade incluem o cometimento de atos inumanos, como o assassinato, perpetrados em um contexto de ataque generalizado ou sistemático contra uma população civil (ORGANIZAÇÃO..., 2009, p. 377-378).

Como se pode notar, o conceito fornecido pelo Estatuto de Nüremberg é extremamente vago. Nessa brecha deixada pelo Direto Internacional é que o Caso Grego adquire relevância, posto que a abordagem da Comissão Europeia de Direitos Humanos é a primeira a enfrentar as delimitações do crime de tortura. Assim, tendo em vista a atualidade do tema, faz-se necessária a análise da herança deixada por este Caso, considerado pertinente.

\section{PANORAMA GERAL DA COMISSÃO EUROPEIA DE DIREITOS HUMANOS - CEDH}

Primeiramente deve-se compreender o funcionamento da Comissão Europeia de Direitos Humanos, que sobreveio como uma consequência da Segunda Guerra Mundial. Durante esse período as nações europeias concordaram em debater e organizar, numa linguagem clara e comum para todos, os princípios básicos dos direitos humanos. 
Em 5 de maio de 1949, cinco nações foram a Londres e assinaram o Estatuto do Conselho da Europa. Já em 1950 o Conselho, que então incluía a Grécia, elaborou o documento intitulado Convenção de Direitos Humanos e Liberdades Fundamentais, que entrou em vigor em 3 de setembro de 1953.

A primeira seção da Convenção estabeleceu a essência do que o Ocidente considera liberdades fundamentais (CANOTILHO, 2003, p. 521): a proteção da vida por lei, a proteção contra tratamento desumano, o direito de casar e de constituir família, de livre associação, o direito à liberdade de pensamento, de consciência e religião. A segunda e terceira partes do tratado discutiam o processo pelo qual as queixas e as violações dos artigos seriam tratadas.

Três instituições eram responsáveis por resguardar esses direitos: A Comissão Europeia dos Direitos do Homem (criada em 1954, com o advento da Convenção), o Tribunal Europeu dos Direitos do Homem (instituído em 1959) e o Comitê de Ministros do Conselho da Europa.

A Convenção também atribuiu ao Comitê de Ministros do Conselho da Europa um poder autônomo de decisão nos casos que não são encaminhados ao Tribunal Europeu de Direitos Humanos, além de competência em matéria de execução, das sentenças do Tribunal, dos casos que foram enviados a este último.

A partir da entrada em vigor de tal Convenção, a Comissão poderia examinar queixas estaduais ou individuais, queixas essas que poderiam advir de qualquer Estado que fosse parte da Convenção, pessoa singular, Organização Não Governamental ou grupo de particulares que fosse parte da Convenção, dado que todas essas personalidades seriam capazes de denunciar à Comissão uma violação da Convenção que acreditavam ter sido cometida por algum Estado contratante. Pelo texto aprovado, os Estados participariam, assim, da manutenção do que se vem chamando de "a ordem pública européia” (PIOVESAN, 2006, p. 66). 
A Comissão é composta por um membro de cada país signatário, que é eleito por seis anos pelo Comitê de Ministros (PIOVESAN, 2006, p.75), entre uma lista de nomes preparada pela Assembleia Parlamentar, sob proposta de cada grupo de representantes das Altas Partes Contratantes. O membro eleito não é considerado representante do Estado de origem e a sua independência é total.

A Comissão não é um órgão permanente, mas é assistida por um Secretariado, este sim ininterrupto, no qual trabalham mais de cem pessoas de diferentes nacionalidades. Além disso, a CEDH possui autonomia para criar e alterar seu regulamento interno, bem como eleger seu presidente.

Para realizar uma queixa não há necessidade da intervenção de um advogado (mesmo que o auxílio de um profissional seja aconselhável) (EUROPEAN..., 1950). Também não há custos, e a petição deve ser dirigida ao Secretário da Comissão. Ademais, sob certas condições, a CEDH pode conceder a assistência judiciária gratuita aos queixosos com recursos modestos, graças aos fundos postos a sua disposição pelo Conselho da Europa.

Em geral, um membro da Comissão atua como relator do processo, que após um exame preliminar pode submeter a queixa a uma Câmara da Comissão, à Comissão plenária ou a um Comitê de três membros para um exame da sua admissibilidade. O relator ou a Comissão podem pedir tanto ao governo como ao queixoso informações factuais sobre as circunstâncias do caso. Ao analisar a queixa, ela pode ser rejeitada sem mesmo dar conhecimento dela ao governo em causa, nos casos em que a sua inadmissibilidade resulta claramente das indicações fornecidas pelo queixoso (EUROPEAN..., 1950).

Se isto não ocorrer, o governo é convidado pela Comissão plenária ou pela Câmara a apresentar por escrito explicações, às quais o queixoso pode responder. As queixas que não geram um conflito, uma polêmica, 
que podem ser analisadas com base numa jurisprudência bem estabelecida, podem ser examinadas por uma Câmara. Se o mérito de uma queixa, contudo, levanta discussões jurídicas peculiarmente delicadas, a Comissão organiza uma audiência, durante a qual os representantes das partes expõem oralmente os seus argumentos (EUROPEAN..., 1950).

Posteriormente, a Comissão (TRINDADE, 1999, p. 126) analisa se as condições de admissibilidade da queixa estão presentes, bem como verifica se o objeto da queixa refere-se a um dos direitos garantidos pela Convenção e se o queixoso cumpriu a obrigação de esgotar os recursos internos. Após a análise, que é feita pela maioria dos membros da $\mathrm{CEDH}$, profere-se uma decisão publicizando a admissão ou não da petição. Tal decisão é irrecorrível, mas o interessado poderá em qualquer caso apresentar uma nova queixa se puder alegar novos fatos. $\mathrm{O}$ queixoso pode também retirar a sua queixa e esta pode ser arquivada sem haver decisão sobre a sua admissibilidade.

Se a queixa for admissível, a Comissão ou a Câmara estabelece os fatos da causa com a colaboração das partes e, se necessário, realiza um inquérito, para cuja realização o governo em causa deverá proporcionar as facilidades necessárias. E então, preliminarmente, realiza-se uma tentativa de conciliação, ocasião em que as partes tentam chegar a uma solução amigável do litígio, que deve se inspirar no respeito dos direitos humanos, tal como eles são reconhecidos pela Convenção (EUROPEAN..., 1950).

Se frutífera, os termos da conciliação são descritos num relatório sumário, que é publicado. Caso a conciliação não seja possível, a Comissão ou a Câmara elabora um relatório (artigo 31), que é enviado ao Comitê de Ministros, bem como ao governo em causa, e também ao requerente, se aplicável. Ele será confidencial (a menos que o caso seja encaminhado ao Tribunal), até que haja uma decisão do Comitê de Ministros. 
Num prazo de até três meses, a Comissão e/ou o governo em causa pode levar o caso ao Tribunal para que este se pronuncie sobre a violação. O particular pode igualmente transmitir o caso ao Tribunal nos termos do Protocolo $\mathrm{n}^{\circ}$ 9. Se aceito pelo Tribunal, a Comissão desempenha a função de advogado geral. Ela não deve se opor a nenhuma das partes, bastando apenas apresentar o seu parecer, que pode, inclusive, ser no sentido da inexistência de violação da Convenção. Se passar esse prazo e o caso não for transmitido, o Comitê de Ministros decide por maioria de dois terços se houve ou não violação da Convenção (o Protocolo $\mathrm{n}^{\circ} 10$ substituiu a regra da maioria de dois terços pela da maioria simples) (PIOVESAN, 2006, p. 72).

Posteriormente entrou em vigor o Protocolo $\mathrm{n}^{\mathrm{o}} 11$, em $1^{\underline{0}}$ de novembro de 1998, que inovou especialmente unificando dois órgãos envolvidos no controle (Comissão Europeia dos Direitos Humanos e o Tribunal Europeu dos Direitos Humanos), substituindo-os por um novo Tribunal único e permanente. Também suprimiu cláusulas facultativas de aceitação do direito de petição individual, permitindo ao indivíduo acesso direto ao Tribunal.

Com a grande demanda possibilitada pelo Protocolo n⿳⺈ 11 (PIOVESAN, 2006, p. 73-74), fez-se necessária a elaboração de algumas medidas com o intuito de simplificar o procedimento, buscando maior celeridade para o funcionamento desse sistema de controle. Assim, foi instituído o Protocolo n. ${ }^{\circ}$ 14, que entrou em vigor no dia $1^{\circ}$ de junho de 2010 .

As mudanças mais significativas que ela (Convenção Europeia dos Direitos Humanos, 1950) trouxe são: (i) a regra do esgotamento dos meios jurisdicionais internos; (ii) o critério adicional de admissibilidade das petições individuais, que exige o requisito de prejuízo significativo; (iii) juiz singular que tem a competência para rejeitar uma petição individual mani- 
festamente inadmissível, cuja decisão de indeferimento será definitiva; (iv) processo simples e acelerado para os casos em que já existe jurisprudência firmada na matéria, entre outras.

Destaca-se, no entanto, que o Caso Grego foi discutido de 1967 a 1969 e, desta forma, seu debate não sofreu influências dos últimos protocolos.

\section{A DITADURA GREGA E A ATUAÇÃO DA COMISSÃO EUROPEIA DE DIREITOS HUMANOS - CEDH}

Feita a devida explicação sobre os mecanismos processuais e estruturais, é importante verificar também o contexto no qual o Caso Grego se insere para que seja possível uma compreensão completa do seu desenvolvimento, conclusão e sua herança conceitual.

A situação desponta numa realidade de instabilidade política após o fim da Segunda Guerra Mundial, que se mantinha em decorrência da tensão causada pelo embate ideológico entre Estados Unidos da América e a antiga União Soviética na chamada guerra fria. Devido a esse atrito, os Estados Unidos, para não perderem força, financiaram diversas ditaduras de direita ao redor ao mundo, incluindo a ditadura grega.

Dessa forma, na manhã do dia 21 de abril de 1967 um golpe militar instaurou uma ditadura pró-americana na Grécia, indo de encontro a todas as negociações realizadas pela Convenção até então, com o consequente desrespeito ao compromisso com os direitos humanos firmado no tratado internacional. Essa série de governos militares que chefiaram o país durante o período 1967-1974 ficou conhecida como "regime dos coronéis".

Pouco antes das eleições programadas para 1967, um grupo de oficiais direitistas do exército grego, liderados pelos então coronéis Papadopoulos, Nikolaos Makarezos e pelo general Stylianos Pattakos, que tinham 
respaldo num “Conselho Revolucionário”, assumiu o poder em um golpe de Estado (SULZBERGER, 1970). O grupo seguia o "Plano Prometheus" que, na realidade, havia sido planejado pela Otan para uma eventual desordem interna na Grécia.

Os motivos oficiais para o golpe de Estado foram os mesmos utilizados no Brasil: uma "conspiração comunista” teria se infiltrado na burocracia estatal, na Academia, na imprensa e em todos os setores da sociedade de forma tão relevante que uma ação drástica se fazia necessária para proteger a nação contra um golpe marxista.

O grupo havia planejado uma tomada de poder surpresa, que desestabilizaria a sociedade. $\mathrm{O}$ comandante Pattakos foi o responsável pelos ataques em posições estratégicas na capital grega, tomando o controle da cidade. Simultaneamente, um grande número de unidades móveis foi deslocado para prender os principais líderes políticos e as autoridades governamentais mais importantes, além de muitos cidadãos comuns suspeitos de "simpatias esquerdistas".

Tendo em vista que as ordens vinham de uma fonte legal, as unidades não envolvidas e os órgãos do governo que não faziam parte da conspiração passaram automaticamente a obedecê-las. $\mathrm{O}$ primeiro dia foi o prenúncio do que seriam os anos seguintes (SULZBERGER, 1970): muitas pessoas foram presas arbitrariamente e algumas delas, como Panagiotis Elis, executadas a sangue frio por jovens oficiais.

Com um início tão sangrento e considerando o passado recente dos totalitarismos europeus, não demorou muito para que uma movimentação ocorresse no Conselho da Assembleia Consultiva da Europa, um fórum constituído por parlamentares integrantes dos Estados-membros. O socialista austríaco Karl Czernetz foi um dos primeiros a fazer uma declaração oficial. Em 25 de abril de 1967, apenas quatro dias após o golpe de Estado, Czernetz se pronunciou: 
Nós ficamos chocados ao saber que na Grécia, o berço do classicismo e da fonte de democracia européia, a democracia foi, mais uma vez abolida, a Constituição violada e uma ditadura militar estabelecida. Um de nossos membros violou os princípios fundamentais de nossa comunidade. Como uma assembléia parlamentar, somos obrigados a tomar uma posição... E devemos exigir a Presidência para lidar com o destino dos deputados gregos que foram designados pelo parlamento grego para ser delegados à Assembléia Consultiva (ANDREAS PAPANDREOU FOUNDATION, 1998).

O representante grego permanente no Conselho Europeu tentou defender os ditadores (EUROPEAN..., 1969, p. 1). Ele argumentou que a Grécia temia medidas contra a democracia e que o Parlamento seria restaurado, uma vez que as condições para tal liberalização estivessem maduras. Essa garantia, porém, não impediu o Conselho de aprovar sua primeira rejeição oficial contra os ditadores, no dia 26 de abril. A Assembleia Parlamentar expressava a tristeza do Conselho Europeu sobre a situação grega e apelou para a Grécia "substituir o regime militar, com uma democracia parlamentar” (EUROPEAN, 1969, p. 1). Apesar da redação sutil, já nesta fase inicial, a maioria dos membros da Assembleia acreditava que a ditadura militar tinha violado a Carta fundamental da Organização, a Convenção.

Entre outras coisas, a Decisão 346 exortou o regime grego a retomar a vida política normal, devendo reestabelecer a democracia conforme a Convenção estabelece. A Grécia, contudo, utilizou-se do artigo 15, que traz uma exceção, possibilitando a um país se desviar da Convenção em tempos de guerra ou de situações de emergência pública que ameaçavam a vida da nação. A Assembleia não se convenceu e argumentou que o governo grego não tinha provado adequadamente a necessidade de suas chamadas medidas de emergência (EUROPEAN..., 1969, p. 18). 
Em setembro do mesmo ano três países, chamados de "Altas Partes Contratantes" na pauta do Conselho (Suécia, Noruega e Dinamarca) levaram o caso contra a Grécia à Comissão Europeia dos Direitos do Homem, com a Holanda se juntando à petição (EUROPEAN..., 1969, p. 18) uma semana depois. Essa foi a primeira vez que uma Alta Parte Contratante realizou uma queixa contra outro Estado na Comissão no interesse de princípios gerais, ou seja, a manutenção da ordem pública europeia e não para promover seus próprios interesses.

O holandês Siegmann foi o primeiro responsável pela elaboração de um relatório sobre a situação na Grécia, no entanto, ao apresentar o resultado do seu trabalho, parecia evitar as questões polêmicas levantadas pela Assembleia, especificamente o que dizia respeito a violações, por parte dos coronéis, dos artigos da Convenção Europeia. O relatório recomendou que apenas no caso de a situação se agravar o Conselho deveria tomar medidas drásticas. Também arguiu que o Conselho deveria esperar até a primavera de 1969 antes de tomar quaisquer novas decisões.

A movimentação no interior da Assembleia fortalecia-se no sentido de investigar novamente a junta militar grega. Assim, o novo responsável seria Max van der Stoel, membro do Partido Trabalhista holandês, que como relator teve a responsabilidade de elaborar um relatório sobre a Grécia sem deixar de citar as questões cruciais.

Ele viajou para a Grécia para investigar as condições do país e entrevistou cidadãos, ex-presos políticos e membros do regime. Seus relatórios convincentes ajudaram a persuadir muitos deputados. Van der Stoel constatou que no caso em questão a tortura era muito mais ampla do que anteriormente conhecida, além de ser um método padrão para o controle sobre a sociedade grega. Enquanto a ditadura grega criticava o relatório de Van der Stoel como “subjetivo” (EUROPEAN..., 1969, p. 28-33), o holan- 
dês manteve-se ocupado. Ele fez mais duas viagens para a Grécia (21-23 de junho e 28 de agosto a $1^{\circ}$ de setembro), quando investigou minuciosamente as condições de presos políticos e o uso da tortura.

Como consequência de seu dinamismo, em dezembro de 1968 o governo grego fez saber ao Conselho que van der Stoel já não tinha permissão para visitar a Grécia. O regime alegou que ele não era mais capaz de continuar com seu papel de relator para a Assembleia sobre o caso grego.

O terceiro relatório do holandês (COUNCIL OF EUROPE, 2002, p. 12), aceito pelo Comitê Político em 28 de janeiro de 1969, foi elaborado sem o benefício de uma visita à Grécia. Nesse documento, o relator concluiu que o atual regime grego não teria cumprido com as condições objetivas necessárias para a participação no Conselho da Europa, tal como definido no artigo $3^{\circ}$ da Convenção, que expressa que ninguém pode ser submetido a torturas, nem a penas ou tratamentos desumanos ou degradantes. Com base neste relatório, a Assembleia votou a Recomendação 547 , ignorando a anterior, que dizia respeito a esperar até a primavera de 1969. E assim declarou abertamente que a Grécia estava violando as condições que lhe permitiriam continuar a ser um membro do Conselho. Como tal, recomendou ao Comitê de Ministros a expulsão da Grécia como uma medida necessária.

O primeiro Conselho de Ministros a lidar com o caso grego foi presidido por Willy Brandt. Embora a recomendação para expulsar a Grécia tenha sido feita em 6 de maio de 1969, o Conselho decidiu adiar qualquer decisão por seis meses, ou seja, até dezembro do mesmo ano. O raciocínio por trás desse atraso, de acordo com o ministro das Relações Exteriores da Grã-Bretanha (EUROPEAN..., 1969, p. 100-101), foi que obrigaria o governo grego a aderir a um prazo, a fim de convencer a opinião pública europeia de que o processo de restauração da democracia, algo que eles alegaram que já havia começado, estava em processo ou em conclusão. 
Ao apreciar o relatório apresentado, a Comissão constatou que dois fatos estavam ocorrendo com frequência: os atos de violência eram repetidos por funcionários estaduais ou ocorriam sob a sua supervisão. Como tais atos eram escondidos ou silenciados pelo governo, os autores não eram punidos e as autoridades superiores, por meio de seu silêncio, se não apoiavam plenamente, ao menos concordavam com tais atos de violência.

Para provar que a Grécia tinha violado o artigo $3^{\circ}$, a Comissão recebeu 941 documentos escritos, examinou 213 denúncias de tortura, ouviu 58 testemunhas, das quais 22 em Estrasburgo e 36 em Atenas. A Comissão também enviou representantes para investigar três locais de detenção na Grécia, e registrou 8 câmaras de tortura na prefeitura da polícia de Atenas e Pireus, 28 em Thessaloniki, 14 em Creta, 9 em outras cidades, e 29 nos escritórios da Polícia Militar; trinta e três agentes da Polícia foram citados como torturadores ou funcionários dos membros mais infames de segurança de Atenas, além de constatar cinco execuções (ANDREAS PAPANDREOU FOUNDATION, 1998).

A Comissão considerou que o governo grego não fez nenhum esforço para impedir, interromper ou punir qualquer torturador, mesmo quando tomava conhecimento dos nomes de ambos, torturador e vítima. A Comissão concluiu que a tortura de presos políticos era um método padrão de controle para o regime de governo (EUROPEAN..., 1969, p. 1).

Os países discutiram a situação e trabalharam na redação da proposta final. O documento afirmava que a Grécia havia violado gravemente a Convenção e argumentava a favor da suspensão da representação grega (COUNCIL OF EUROPE, 2002, p. 12). A Comissão manifestou o seu desagrado pelo fato de o governo grego não ter tomado as medidas adequadas para o restabelecimento dos direitos humanos e das liberdades fundamentais, bem como da democracia. 
Enquanto os ministros estavam falando, o ministro das Relações Exteriores grego subitamente interrompeu o processo e disse aos ministros que a Grécia iria denunciá-los e que deixaria o Conselho da Europa, por sua livre e espontânea vontade (COUNCIL OF EUPORE, 2002, p. 12). Desta forma a Grécia conseguiu evitar, no último minuto, uma decisão formal contra o regime militar.

Mesmo não ocorrendo uma decisão de fato, este caso destaca-se por diversas razões, à medida que esta foi a primeira vez que o Conselho Europeu e a Comissão de Direitos Humanos enfrentou uma situação em que os direitos humanos haviam sido tão esmagadora e sistematicamente violados, dado que, até então, a maioria dos casos abordados pelo Conselho foram violações individuais ou violações bilaterais da Convenção inicial. Além disso, esta foi a primeira vez que um caso foi levado ao Conselho por membros que não tinham interesse imediato. O Caso Grego deu ao Conselho da Europa e, especialmente, à Assembleia Consultiva, a oportunidade de explorar e exercer o seu potencial ao máximo.

\section{CONCLUSÕES SOBRE AS CONSEQUÊNCIAS PARA CRIME DE TORTURA}

O Caso Grego protagonizou a primeira análise minuciosa do crime de tortura. Graças a este evento, não apenas o conceito internacional de tortura, mas a forma com que este crime é tratado pelos tribunais mudou. E a influência não se restringiu apenas a estas transformações, mas também é exercida nas decisões dos tribunais internacionais de direitos humanos que continuam a citar o ocorrido.

No caso em questão, a CEDH classificou a tortura como um tipo acentuado de ato desumano, imposto a alguém com um fim específico, como obter informação, confissão, etc. E foi este entendimento que em 
1975 a ONU adotou na Resolução 3.452, afirmando que a tortura é uma pena excessiva e planejada ou um tratamento "cruel, desumano e degradante" (ONU, 1975).

Essa definição foi responsável por inspirar uma Convenção realizada pela ONU em 1984, para pormenorizar o tema, definindo a prática de tortura no âmbito legal internacional. Conhecida como a Convenção das Nações Unidas contra a Tortura e outros Tratamentos ou Penas Cruéis, Desumanos e Degradantes, fornece um conceito uniforme e cognoscível sobre a proibição da tortura, para facilitar a efetivação e fiscalização internacional da Convenção.

Dessa forma, graças às análises e discussões minuciosas realizadas no Caso Grego, a tortura já está tipificada internacionalmente. Sua definição abrange todo e qualquer ato, praticado por agente público ou por quem esteja investido na função, que cause severo sofrimento, físico ou mental, a alguém em razão de determinado motivo.

A intensidade da dor ou do sofrimento para que se constitua tortura ainda é considerada uma questão vaga, sendo deixada a cargo do testemunho da vítima, utilizando o mesmo método que se pode aferir no relatório do Caso. Assim, o precedente é de que tribunais devem analisar as consequências da ação sobre a vítima quando tiverem de decidir se a tortura ocorreu ou não (INGELSE, 2001, p. 209). E neste sentido a compreensão da "tortura não física" é ainda mais complexa, tendo em vista a definição dada pela Comissão Europeia de Direitos Humanos, ou seja, aquele tratamento que impõe sofrimento mental, criando um estado de angústia e estresse por meios outros que não agressão física (RODLEY, 1999, p. 90).

Já a motivação, citada no artigo $1^{\circ}$ da Convenção, é a razão, é a justificativa para a prática da tortura. As justificativas mais comuns para a prática de tortura foram analisadas de forma localizada no Relatório da ONG Conectas citado no início, e se confundem com os motivos globais, que são (ORGANIZAÇÃO..., 2010): 1) meio de obtenção de prova - para descobrir 
crimes, obter a confissão do acusado ou a incriminação de alguém, e de forma a intimidar outros suspeitos; 2) punição - meios cruéis de aplicação de pena; 3 ) particular - não praticada pelo Estado, mas por instintos individuais baixos, como vingança, ódio, ira, inveja, ou, muitas vezes, que denotam sadismo. O Relatório também demonstra o poder dos tribunais de identificar, no caso concreto, a motivação do torturador, posto que o artigo não é taxativo.

A intencionalidade da tortura é a consequência de uma ação empreendida após consulta/reflexão, e neste caso especificamente, é a intenção/ vontade do perpetrador de causar grave sofrimento a alguém. Apenas os atos cometidos por alguém de forma deliberada são passíveis de constituir tortura. Dor ou sofrimento infligidos acidentalmente não podem constituir tortura (RODLEY, 1999, p.78). Assim, torturar é manipular a dor, submetendo alguém à vontade de outro pela imposição de dor física ou intenso sofrimento mental.

Ao contrário da lei brasileira, em que a tortura pode ser cometida por agente público e privado, a Convenção Contra a Tortura a caracteriza como um crime próprio de agente público, restringindo a prática de tortura a atos realizados com consentimento ou por instigação de funcionários públicos, ou por pessoas nessa função. Essa medida teve o fim de restringir o crime de tortura àqueles praticados por agentes do Estado. Como se pode aferir pelo Relatório da Conectas e pelo Caso Grego, os remédios nacionais normalmente não são eficazes, pelos já citados corporativismo e a dificuldade de fazer prova do crime (RODLEY, 1999, p. 100). Essas condições acabam gerando empecilhos para a responsabilização e prevenção dos atos de tortura cometidos por agentes estatais, criando um ciclo de violência e impunidade.

Além disso, como esse artigo possui um excludente de tipicidade geral e amplo, muitos Estados tentaram (e tentam) embasar as suas defesas com a justificativa de "sanção legítima”, reproduzindo a infértil tentativa grega, de forma a dissimular a prática de tortura. O relator especial, no entanto, sustentou que esta exclusão deve necessariamente se refe- 
rir àquelas sanções que constituem práticas extensamente aceitas como legítimas pela comunidade internacional, como a privação de liberdade mediante o aprisionamento, etc. (INGELSE, 2001, p. 232).

Desta forma, mesmo com a existência de um ordenamento jurídico que tratava de crimes de lesa-humanidade, como foi o caso do Estatuto de Nüremberg, foi apenas com a ditadura na Grécia e o Caso Grego que o crime de tortura pôde ser tratado de forma específica. E com isso, a interpretação do que seria o crime de tortura, bem como a forma de julgá-lo e analisá-lo mudou, demonstrando pelos diversos pontos aqui enfatizados a atual relevância deste caso para o Direito Internacional.

\section{REFERÊNCIAS}

ANDREAS G. PAPANDREOU FOUNDATION. The Council of Europe Fights for Democracy in Greece. 1998. Disponível em: <http://www.agp.gr/agp/content/Document.aspx?d=7\&rd=5499005\&f=1426\&rf=1866356962\&m=4735\&r $\mathrm{m}=9703031 \& \mathrm{l}=1>$. Acesso em: 28 fev. 2016 .

CANOTILHO, J. J. G. Direito constitucional e teoria da constituição. 7. ed. Coimbra: Almedina, 2003.

COUNCIL OF EUROPE. Human Rights Handbooks: The prohibition of torture, n. 6. Germany: Council of Europe, 2002.

EUROPEAN COMMISSION ON HUMAN RIGHTS. Greek Case, Commission Report of 5 November 1969, Yearbook 12. Disponível em: <file://C:/Users/ pc/Downloads/001-142536.pdf>. Acesso em: 13 abr. 2016.

EUROPEAN COURT OF HUMAN RIGHTS (ECHR). Convenção europeia dos direitos humanos com as devidas alterações dos protocolos. 1950. Disponível em: <http://www.echr.coe.int/Documents/Convention_POR.pdf $>$. Acesso em: 2 mar. 2016.

INGELSE, C. The UN Committee against Torture: An assessment. The Hague; London; Boston: Kluwer Law International, 2001. 
ORGANIZAÇÃO NÃO GOVERNAMENTAL. ONG Conectas. Julgando a tortura: análise de jurisprudência nos tribunais de justiça do Brasil. 2010. Disponível em: <http://www.conectas.org/arquivos/editor/files/Julgando\%20a\%20 tortura.pdf $>$. Acesso em: 16 fev. 2016.

ORGANIZAÇÃO DAS NAÇÕES UNIDAS (ONU). Declaração sobre a proteção de todas as pessoas contra a tortura ou outros tratamentos ou penas cruéis, desumanos ou degradantes - 1975. Disponível em: <http://www.direitoshumanos.usp.br/index.php/Direitos-Humanos-na-Administra\%C3\%A7\%C3\%A3o-da-Justi\%C3\%A7a.-Prote\%C3\%A7\%C3\%A3o-dos-Prisioneiros-e-Detidos.-Prote\%C3\%A7\%C3\%A3o-contra-a-Tortura-Maus-tratos-e-Desaparecimento/ declaracao-sobre-a-protecao-de-todas-as-pessoas-contra-a-tortura-ou-outros-tratamentos-ou-penas-crueis-desuma.html>. Acesso em: 16 fev. 2016.

. Yearbook of the International Law Commision, 1950, Vol. II, Documents of the Second Session including the Report of the Commision to the General Assembly, New York, 1957.

. Report of the Commission of the General Assembly, Part III Formulation of de Nüemberg Principles, p. 374-378. In: SOARES, Inês Virgínia Prado; KISHI, Sandra Akemi Shimada (Coord.). Memória e verdade: a justiça de transição no Estado democrático brasileiro. Belo Horizonte: Fórum, 2009. PIOVESAN, F. Direitos humanos e justiça internacional: um estudo comparativo dos sistemas regionais europeu, interamericano e africano. São Paulo: Saraiva, 2006.

RODLEY, Nigel. The treatment of prisoners under international law. London: Oxford University Press, 1999.

SULZBERGER, C. L. Greece under the Colonels. In: Foreign affairs magazine, 1970. Disponível em: <http://www.foreignaffairs.com/articles/24138/c-l-sulzberger/greece-under-the-colonels $>$ Acesso em: $1^{\circ}$ mar. 2016.

TRINDADE, A. A. C. Tratado de direito internacional dos direitos humanos. Porto Alegre: Sergio Fabris Editor, 1999. Vol. III.

Recebido em: $14 / 7 / 2016$

Revisões requeridas em: 19/8//2016

Aceito em: 23/8/2016 